\title{
Spectrin Subtypes in Mammalian Brain: An Immunoelectron Microscopic Study
}

\author{
Ian S. Zagon, ${ }^{\star}$ Russell Higbee, ${ }^{*}$ Beat M. Riederer, $\dagger$ and Steven R. Goodman $\dagger$ \\ Departments of *Anatomy and †Physiology, The Milton S. Hershey Medical Center, The Pennsylvania State \\ University, Hershey, Pennsylvania 17033
}

\begin{abstract}
Spectrin is a major cytoskeletal component of the brain. At least 2 distinct spectrin subtypes are found in mammalian brain: brain spectrin(240/235) and brain spectrin(240/235E). In the present study spectrin subtypes were localized in the adult mouse brain by immunoelectron microscopy using antibodies that recognize each subtype. Brain spectrin(240/235E) was concentrated in neuronal cell bodies, dendrites, and postsynaptic terminals. It was also prominently associated with the plasma membrane, microtubules, filaments, mitochondria, endoplasmic reticulum, and nuclear envelope, and it appeared to interconnect structural elements within the cell. Brain $\operatorname{spectrin}(240 / 235 E)$ also was localized to the plasma membrane, nuclear envelope, and cytoplasmic organelles of glial cell bodies. Brain spectrin(240/235) was detected in axons and presynaptic elements, where it was associated with the plasma membrane, microtubules, filaments, synaptic vesicles, and mitochondria. These results show that (1) spectrin is distributed throughout the cytoplasm of neural cells, (2) the location of spectrin is dependent on subtype, and (3) the cytoplasmic surface of plasma membrane and organelles contains an extensive and intricate spectrin meshwork.
\end{abstract}

Brain spectrin is an analog of erythrocyte spectrin, which, like its erythrocyte counterpart, is an elongated fibrous protein of $2000 \AA$ contour length, with a molecular weight of $1 \times 10^{6} \mathrm{Da}$ and an $(\alpha \beta)_{2}$ tetrameric subunit composition (for review, see Goodman and Zagon, 1984, 1986). The $\alpha$-subunits of brain and red blood cell (rbc) spectrin have an apparent molecular weight of $240 \mathrm{kDa}$, while the $\beta$-subunits are $235 \mathrm{kDa}$ (brain) and 220 $\mathrm{kDa}$ (rbc). Other similarities between brain and rbc spectrin include binding sites for actin at the terminal ends of the molecule (Glenney et al., 1982), a binding site for brain ankyrin $800 \AA$ from the end of the $\beta$-subunit (Davis and Bennett, 1984), a binding site for brain protein 4.1 at the ends of the molecule (Goodman and Zagon, 1986), and a phosphorylated $\beta$-subunit (Goodman et al., 1983). In the case of mammalian brain spectrin, both the $\alpha$ - and $\beta$-subunits are distinct gene products from rbc spectrin $\alpha$ - and $\beta$-subunits (for reviews, see Glenney and Glenney, 1983; Goodman and Zagon, 1984, 1986).

Fodrin, a molecule we now know to be equivalent to brain spectrin, has been localized to the cortical cytoplasm of guinea pig neuronal cell bodies, axons, and dendrites, as well as Schwann cells (Levine and Willard, 1981), using an antibody directed against the $240 \mathrm{kDa} \alpha$-subunit of brain spectrin (Cheney et al., 1983). Zagon et al. (1984), using an antibody against mouse rbc spectrin, which detected 240 and $235 \mathrm{kDa}$ polypeptides exclu-

Received Nov. 21, 1985; revised Jan. 27, 1986; accepted Mar. 28, 1986.

This work was supported in part by NIH Grants NS-21246, NS-20623, and NS-20500 (I.S.Z.), and Grants NS-19357 and HL-26059 (S.R.G.). S.R.G. is an Established Investigator of the American Heart Association.

Correspondence should be addressed to Dr. Ian S. Zagon at the above address. Copyright $\odot 1986$ Society for Neuroscience $0270-6474 / 86 / 102977-10 \$ 02.00 / 0$ sively on immunoautoradiography of total mouse brain protein, localized brain spectrin to neuronal cell bodies and dendrites, but not axons. Staining of glial cell bodies with rbc spectrin antibody was also observed (Zagon et al., 1984). This apparent discrepancy concerning brain spectrin localization has recently been reconciled by the discovery that 2 forms of spectrin exist in mammalian neural tissue (Riederer et al., 1986; for review, Goodman and Zagon, 1986). Brain spectrin(240/235) is present in axons and, to a lesser extent, in neuronal cell bodies but is not found in dendrites or glial cell types. This axonal spectrin subtype is not recognized by rbc spectrin antibodies. Brain spec$\operatorname{trin}(240 / 235 \mathrm{E})$ is found in neuronal cell bodies and dendrites but not in axons. $\mathrm{RBC}$ spectrin antibodies recognize exclusively this brain spectrin subtype. Glial cells are also stained with rbc spectrin antibody on immunohistochemical analysis, suggesting that they contain a protein antigenically related to spectrin(240/ $235 \mathrm{E})$. Two forms of brain spectrin have been detected in chicken brain (Lazarides and Nelson, 1983). One form detected by an antibody against chick rbc $\beta$-spectrin had subunits of 240 and $230 \mathrm{kDa}$ and was localized in cell bodies and dendrites of neuronal cells. The other form was detected with an antibody against chicken rbc $\alpha$-spectrin, had subunits of 240 and 235 $\mathrm{kDa}$, and was localized throughout neuronal cells (axons, cell bodies, and dendrites). Therefore, the isoforms of spectrin found in chicken brain are similar, but not identical, in composition and location to the mammalian brain spectrin subtypes.

All studies performed to date concerning brain spectrin localization have utilized immunohistochemical analysis at the light-microscope level of resolution. Yet to understand brain spectrin function, we need to know which neural membranes, organelles, and/or cytoskeletal structures contain associated spectrin; these questions are beyond the resolution of the light microscope. In this report, we describe the localization of brain $\operatorname{spectrin}(240 / 235)$ and brain $\operatorname{spectrin}(240 / 235 \mathrm{E})$ within mouse cerebellum utilizing immunoelectron microscopy.

\section{Materials and Methods}

\section{Animals}

Adult male C57BL/6 mice (Jackson Laboratories, Bar Harbor, ME) were utilized in this study and were housed under controlled conditions (Zagon and McLaughlin, 1981). All animals were allowed at least $5 \mathrm{~d}$ to acclimate to their surroundings prior to the beginning of experimentation.

\section{Spectrin isolation}

Brain spectrin(240/235) was isolated from a synaptic/axonal membrane preparation from perfused mouse brains as previously described (Riederer et al., 1986). Mouse rbc spectrin was isolated by low-ionic-strength extraction of isolated rbc membranes followed by rate zonal sedimentation through sucrose gradients or Sepharose $4 \mathrm{~B}$ chromatography as previously described (Goodman and Weidner, 1980; Goodman et al., 1982). 


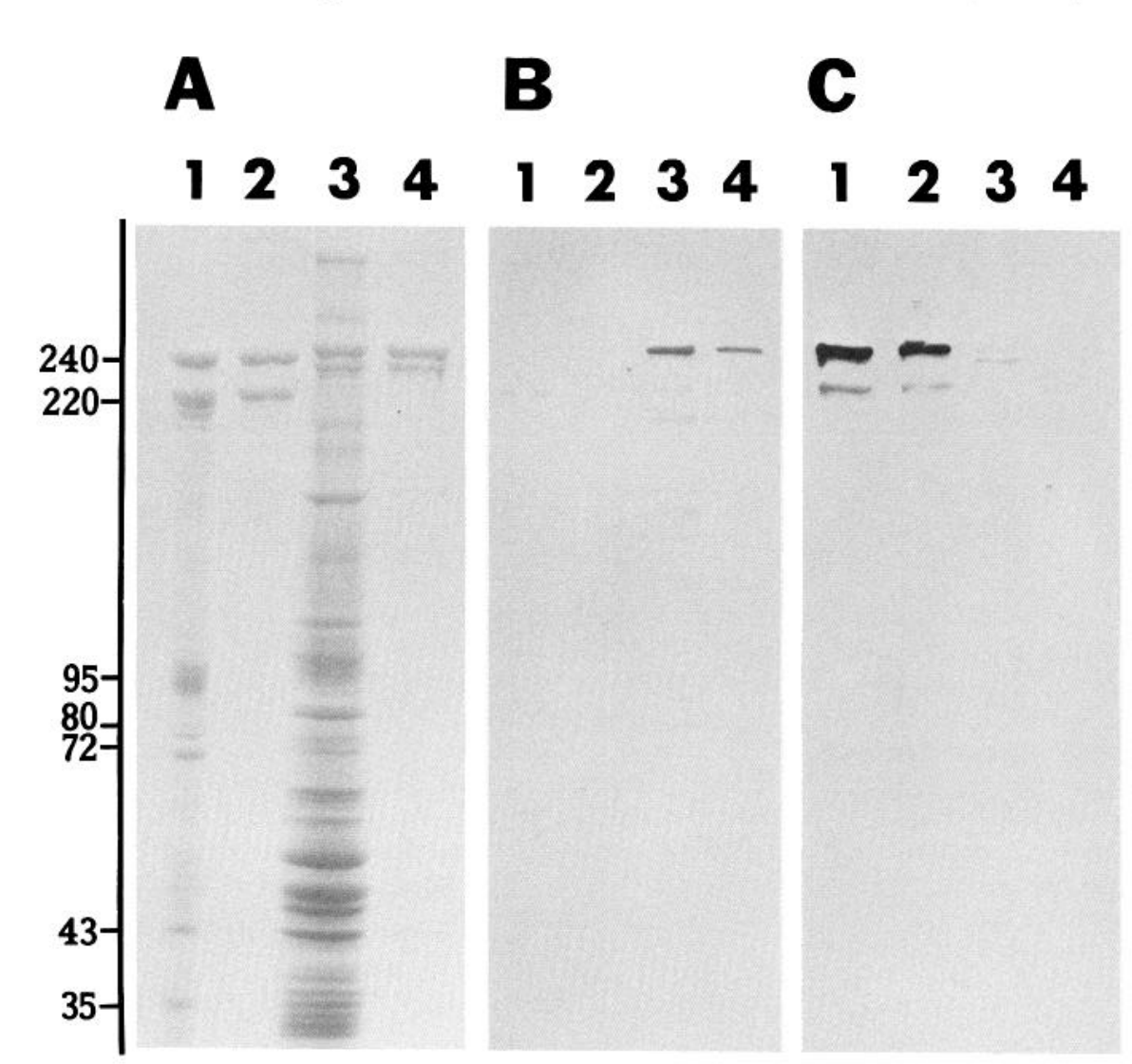

Figure 1. Immunoblots with mouse rbc spectrin and mouse brain spectrin(240/235) antiserum: (1) mouse rbc membrane protein, (2) purified mouse rbc spectrin, (3) mouse brain homogenate protein, and (4) purified brain spectrin $(240 / 235)$ were electrophoresed on $5-15 \%$ polyacrylamide gradient SDS gels and stained with Coomassie blue $(A)$ or transferred to nitrocellulose paper $(B, C)$. Proteins bound to nitrocellulose paper were stained with brain spec$\operatorname{trin}(240 / 235)$ antiserum $(B)$, or rbc spectrin antiserum $(C)$, followed by HRP-conjugated goat anti-rabbit IgG. Note that rbc spectrin antiserum does not stain purified brain spectrin $(240 /$ 235), but does react with another spectrin subtype [brain spectrin(240/ $235 \mathrm{E})]$ in the total brain homogenate.

\section{Antibody preparation and characterization}

Native homogeneous mouse brain spectrin(240/235) and rbc spectrin were used as immunogens in rabbits as described (Goodman et al., 1981). The antisera against $\mathrm{rbc}$ and brain spectrin(240/235) were passed through either a brain or rbc spectrin-Sepharose 4B column, respectively, to yield antisera that would only detect the original antigen (Riederer et al., 1986). We have recently published an extensive characterization of these antibodies, including immunodot, immunoblot, and immunohistochemical analysis. The results of these analyses demonstrated that the rbc spectrin antiserum detected only brain spectrin(240/ 235E) from total brain homogenate protein after affinity chromatography. The antiserum against the synaptic/axonal form of spectrin was specific for brain spectrin(240/235) after affinity chromatography (Riederer et al., 1986).

\section{SDS-PAGE and immunoblots}

SDS-PAGE was performed utilizing $5-15 \%$ polyacrylamide gradient gels and a discontinuous buffer system (Laemmli, 1970). Proteins were transferred from the SDS-polyacrylamide slab gels to nitrocellulose filters (Millipore) by the method of Towbin et al. (1979). Immunoblots were performed by the immunoperoxidase method utilizing antisera at a 1:1000 dilution, as described by Riederer et al. (1986).

\section{Immunoelectron microscopy}

Mice were anesthetized with $0.3 \%$ chloral hydrate and perfused through the heart with a fixative solution containing $1 \%$ glutaraldehyde, $4 \%$ paraformaldehyde, and $0.25 \%$ sucrose in $0.1 \mathrm{~m}$ Sorenson's phosphate buffer $\left(\mathrm{pH} 7.4,20^{\circ} \mathrm{C}\right)$ for $5 \mathrm{~min}$ at $100-120 \mathrm{~mm} \mathrm{Hg}$. The brain was immediately removed and postfixed in $4 \%$ paraformaldehyde in $0.1 \mathrm{M}$ Sorenson's phosphate buffer and $0.25 \%$ sucrose overnight at $4^{\circ} \mathrm{C}$. Vibratome sections, $50 \mu \mathrm{m}$ (Oxford Vibratome, Electron Microscopy Sciences), of the cerebellum were cut in sagittal and coronal planes in Sorenson's buffered saline $\left(4^{\circ} \mathrm{C}\right)$; when necessary, sections were stored in Sorenson's phosphate buffer containing $0.01 \%$ sodium azide at $4^{\circ} \mathrm{C}$.

For conventional morphological examination, adult mice were perfused through the heart with $2 \%$ glutaraldehyde and $4 \%$ paraformaldehyde in $0.1 \mathrm{~m}$ Sorenson's phosphate with $0.25 \%$ sucrose $(\mathrm{pH} 7.4$, $20^{\circ} \mathrm{C}$ ). Cerebella were removed and postfixed in fresh fixative overnight at $4^{\circ} \mathrm{C}$. Vibratome sections were postfixed in $1 \%$ osmium tetroxide in Sorenson's phosphate buffer with $0.25 \%$ sucrose for $1 \mathrm{hr}\left(4^{\circ} \mathrm{C}\right)$, and tissues were dehydrated and processed for electron microscopy as described below.

For immunocytochemistry, sections were preincubated with $5 \mathrm{mg} /$ $\mathrm{ml}$ normal goat serum (NGS) in PBS for $30 \mathrm{~min}$ at room temperature. Sections were incubated with either rabbit anti-mouse rbc spectrin or anti-mouse brain spectrin(240/235) (1:200 dilution). Control specimens were incubated in preimmune IgG (1:200 dilution) or anti-rbc or antibrain spectrin antibodies preabsorbed with an excess of rbc or brain spectrin(240/235), respectively. Tissues were washed in PBS for $2 \mathrm{hr}$ with 4 changes of solution. Sections were incubated for $3 \mathrm{hr}$ with peroxidase conjugated goat anti-rabbit IgG (Cappel Laboratories, Division of Cooper Biomedical, Inc.) diluted 1:200 with PBS, and washed for 2 $\mathrm{hr}$ (4 changes of PBS solution). Sections were reacted with diaminobenzidine tetrahydrochloride ( $30 \mathrm{mg} / 50 \mathrm{ml}$ PBS; Sigma) containing 10 $\mu 1$ hydrogen peroxide for $5-10 \mathrm{~min}$. The reaction was terminated by washing in PBS solution and the reaction product intensified by immersion of the tissues in $1 \%$ osmium tetroxide and $0.1 \mathrm{~m}$ Sorenson's phosphate buffer for $30 \mathrm{~min}$ at $4^{\circ} \mathrm{C}$. The tissue sections were dehydrated in a graded series of alcohols and embedded in Epon.

Thin sections were cut with a Reichert OMU-2 ultramicrotome and mounted on 200 and 300 mesh slotted copper grids. Sections of specimens prepared for conventional electron microscopy were stained with uranyl acetate and lead citrate. Tissues prepared for immunoelectron microscopy were not stained. Specimens were examined with a Philips 300 or $400 \mathrm{EM}$ at accelerating voltage of $60 \mathrm{kV}$.

\section{Results}

Characterization of the antisera against mouse rbc spectrin and brain spectrin(240/235)

The antisera against mouse rbc spectrin and mouse brain spectrin(240/235) used in this study have been extensively characterized (Riederer et al., 1986). In brief, antisera against mouse rbc spectrin after passage through a brain spectrin(240/235)Sepharose $4 \mathrm{~B}$ column reacts exclusively with the 240 and 220 


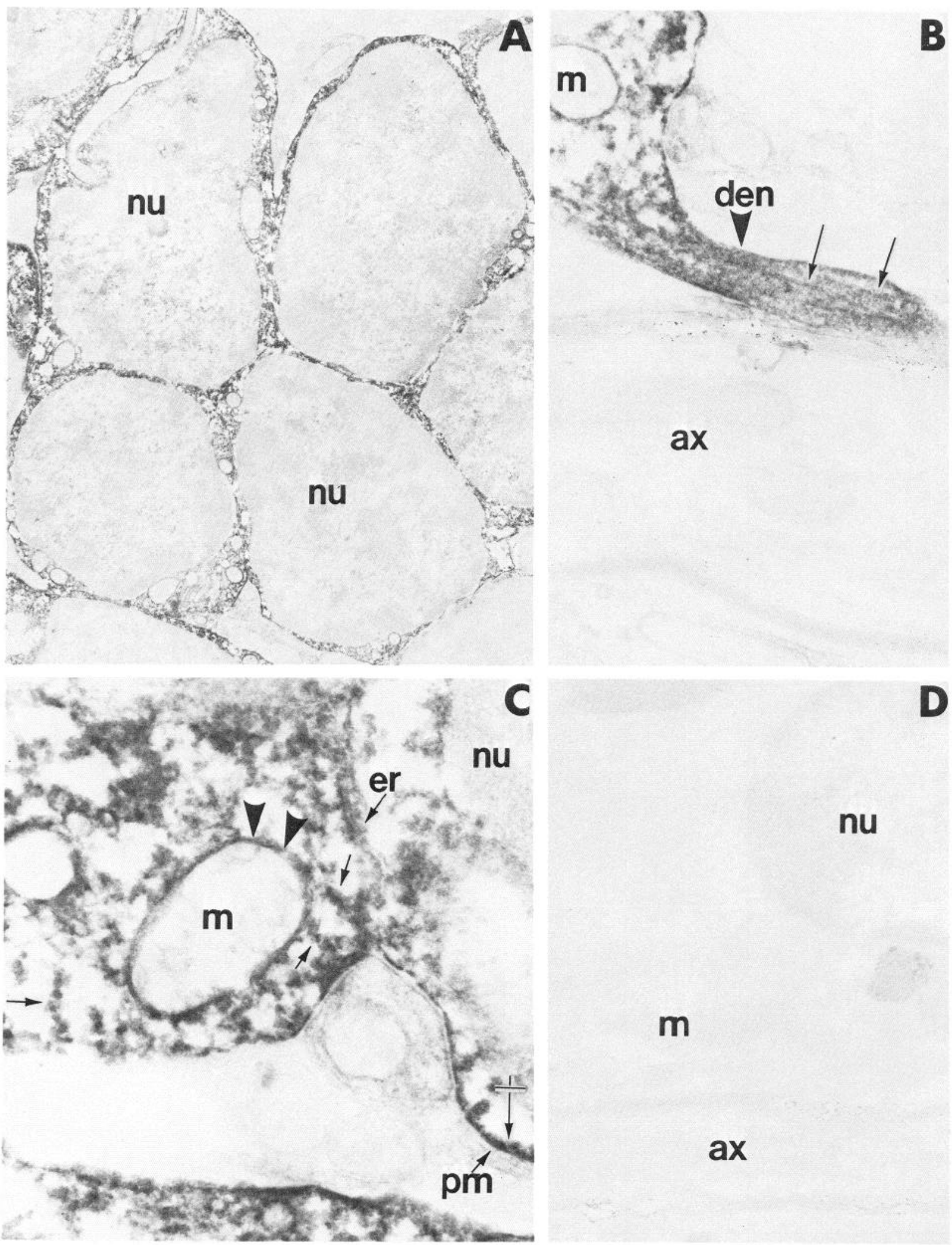

Figure 2. Electron micrograph of the cerebellar cortex of adult mouse. Unless otherwise noted, all tissues were stained with anti-rbc spectrin IgG and peroxidase-conjugated goat anti-rabbit IgG. $A$, Low-magnification photomicrograph of internal granule neurons. The cytoplasm of these cells was intensely stained, but cell nuclei $(n u)$ demonstrated little immunoreactivity. $\times 9200 . B$, Dendrite $($ den $)$ of an internal granule neuron. Note the peroxidase activity surrounding the mitochondrion $(\mathrm{m})$ and the staining of microtubule-like structures (arrows) in the dendrite. Myelinated axons (ax) exhibited little immunoreactivity to anti-rbc spectrin IgG. $\times 15,000$. C, Cytoplasm of internal granule neurons, but not cell nuclei ( $n u$ ), was prominently stained. Peroxidase was associated with endoplasmic reticulum (er) and the nuclear membrane, and it was often found in aggregates (arrowheads) around mitochondria $(\mathrm{m})$. Stain was located subjacent (cross-hatched arrow) to the plasma membrane ( $\mathrm{pm}$ ), and "strands" of stain (arrows) were noted to interconnect structural elements in the cytoplasm. $\times 49,300 . D$, Internal granule neurons $(n=$ nucleus; $m=$ mitochondria) and myelinated axons $(a x)$ of a control specimen stained with anti-rbc spectrin IgG absorbed with rbc spectrin. $\times 22,000$. 

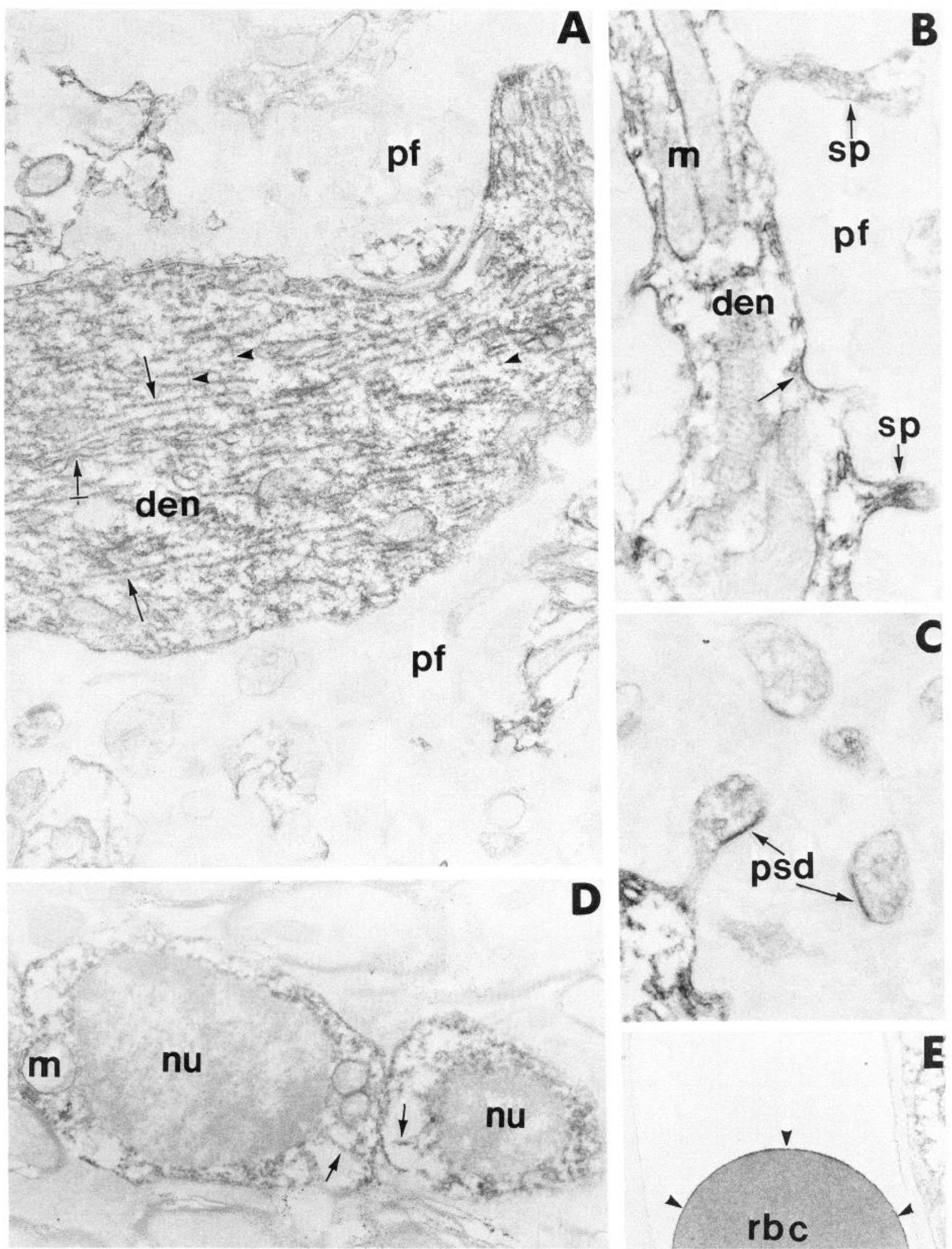

Figure 3. Electron micrograph of the cerebellar cortex of adult mouse. All tissues were stained with anti-rbc spectrin IgG and peroxidase-conjugated goat anti-rabbit IgG. $A$, In this sagittal section of the molecular layer, unstained parallel fibers ( $p f$ ) surround a prominently immunoreactive Purkinje cell dendrite (den). Stain was associated with microtubules (arrows) and neurofilaments (cross-hatched arrow); small, thin "strands" of stain (arrowhead), oriented perpendicular to the microtubules, often were observed to be interconnecting microtubular elements. $\times 20,000$. B, Purkinje cell dendrite (den) stained with anti-rbc spectrin IgG, surrounded by parallel fibers $(p f)$ with little immunoreactivity. Stain extended into the synaptic spines $(s p)$ and was also noted in the dendritic shaft, where axodendritic synapses occurred (arrow). $m=$ mitochondrion. $\times 30,000$. $C$, Synaptic spines related to Purkinje cell dendrites in the molecular layer display considerable immunoreactivity. Postsynaptic densities (psd) are stained. $\times 30,000$. D, Oligodendrocyte in the medullary layer. Stained cytoplasm encircles an unstained nuclear region $(n u)$. As in neuronal cells, "strands" of peroxidase (arrows) connect many structures in the cytoplasm. $m=$ mitochondrion. $\times 13,500$. $E$, An erythrocyte ( $r b c)$ in a capillary located in the internal granule layer. Staining is particularly prominent subjacent to the plasma membrane (arrows). $\times 14,000$. 


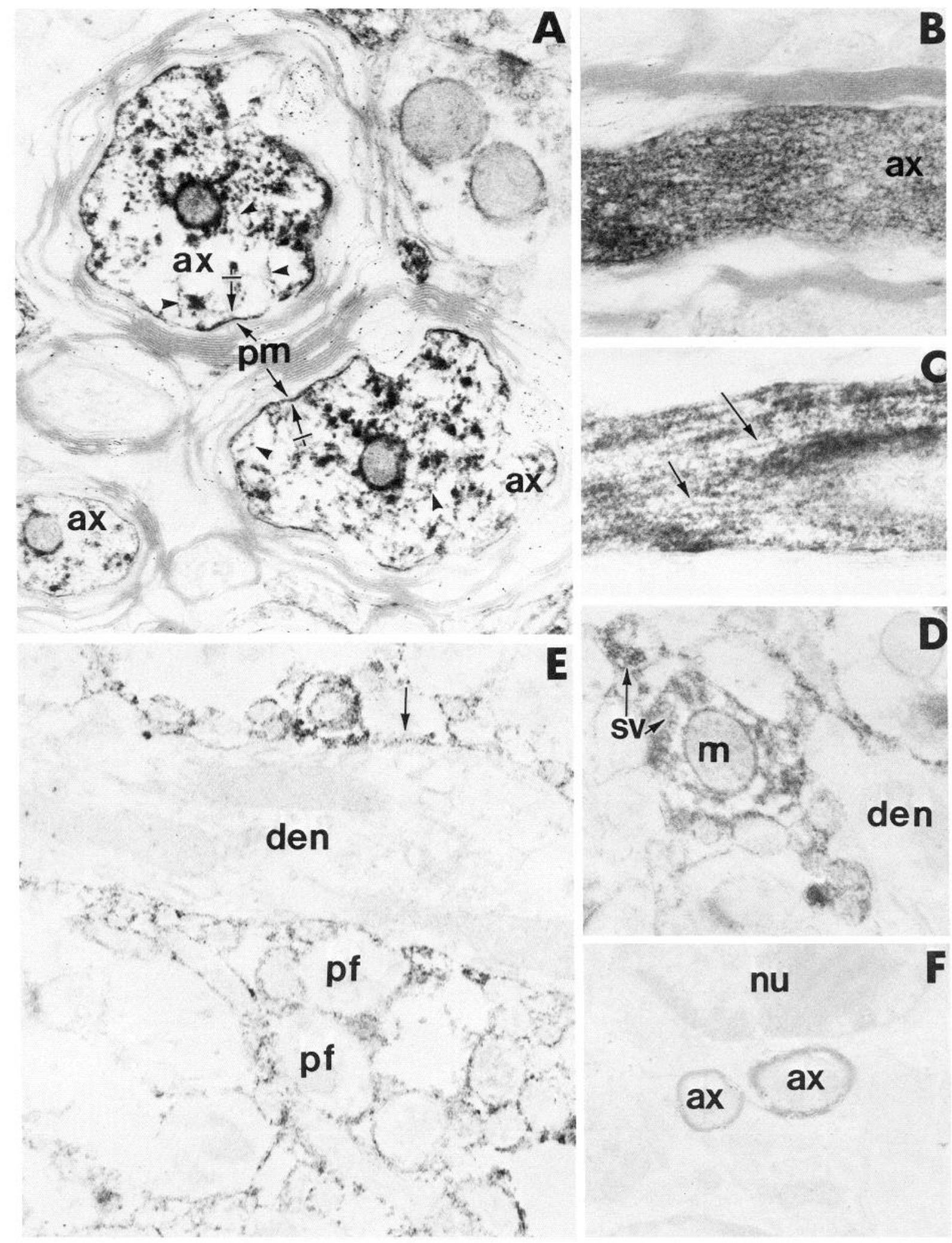

Figure 4. Electron micrograph of the cerebellar cortex of adult mouse. Unless otherwise noted, all tissues were stained with anti-brain spectrin(240/ $235)$ and peroxidase-conjugated goat anti-rabbit IgG. $A$, Cross-section of myelinated axons $(a x)$ in the medullary layer. Stain is located subjacent (crosshatched arrows) to the plasma membrane $(\mathrm{pm})$ and surrounds a centrally located mitochondrion in each of the 3 axons indicated. "Strands" of staining product (arrowhead) appear to interconnect cellular structures. $\times 38,000 . B$, Myelinated axon $(a x)$ in the medullary layer. Note the staining of microtubule-like elements (arrows). $\times 55,000$. C, An axon in the medullary layer. Note the staining of microtubule-like elements (arrows). $\times 55,000$. $D$, Axonal terminals in the molecular layer containing synaptic vesicles $(s v)$ and mitochondria $(m)$ were notably stained with anti-brain spectrin $(240 / 235)$. Dendrites (den) demonstrated little immunoreactivity. $\times 32,500$. E, In the molecular layer, dendrites (den) showed little staining with anti-brain spectrin(240/235); however, parallel fibers ( $p f$ ) were stained. Axonal contacts along the shaft of dendrites (arrow) were noted to be intensely immunoreactive. $\times 25,000 . F$, Border of the internal granule and medullary layers showing an internal granule neuron $(n u=$ nucleus) and myelinated axons $(a x)$ with no immunoreactivity, in tissues stained with preimmune IgG. The electron-dense zones around the axons are unstained myelin. $\times 14,000$. 

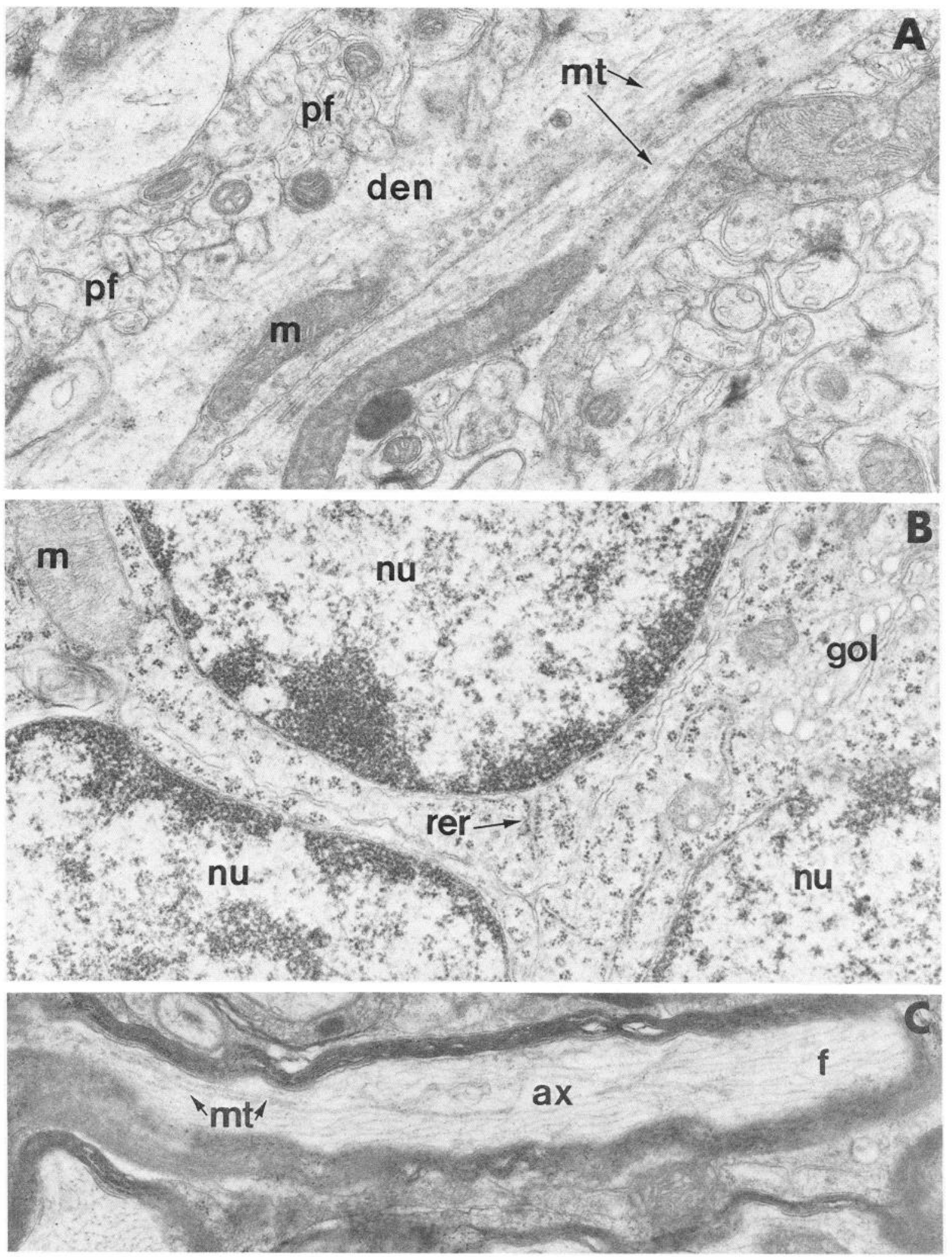

Figure 5. Electron micrograph of the cerebellar cortex of adult mouse. Conventionally prepared tissues of the cerebellar cortex showing structural details of representative areas of the molecular $(A)$, internal granule $(B)$, and medullary $(C)$ layers. $A$, In this sagittal section a Purkinje cell dendrite $(d e n)$ containing microtubules $(m t)$ and mitochondria $(m)$, and surrounded by parallel fibers of internal granule neurons $(p f)$, can be seen. $\times 28,000$. $B$, Internal granule neurons ( $n u=$ nucleus) with a thin rim of cytoplasm that includes rough endoplasmic reticulum (rer), a Golgi apparatus ( $g o l)$, mitochondria $(m)$, and numerous polyribosomes. $\times 28,000$. $C$, In this longitudinal section of a myelinated axon $(a x)$ in the medullary layer, microtubules $(m t)$, and neurofilaments $(f)$ can be observed. $\times 28,000$. 
$\mathrm{kDa}$ subunits of mouse rbc spectrin on immunoblots of total mouse rbc membrane protein or purified mouse rbc spectrin (Fig. $1 C$, lanes 1 and 2). After affinity chromatography, this antibody does not cross-react with purified brain spectrin $(240 /$ 235 ) isolated from synaptic/axonal membranes (Fig. $1 C$, lane 4). However, this antiserum does cross-react with the 240 and $235 \mathrm{kDa}$ subunits of brain spectrin(240/235E) on immunoblots of total brain protein (Fig. $1 C$, lane 3 ). The antisera preferentially detect the $235 \mathrm{kDa}$ subunit of brain spectrin(240/235E).

The antisera against brain spectrin(240/235), after passage through an rbc spectrin-Sepharose $4 \mathrm{~B}$ affinity column, does not react with rbc spectrin on immunoblots of total mouse rbc membrane protein or purified mouse rbc spectrin (Fig. $1 B$, lanes 1 and 2). This antibody specifically stains the $240 \mathrm{kDa} \alpha$-subunit of brain spectrin(240/235) on immunoblots of total mouse brain protein and purified mouse brain spectrin(240/235) (Fig. $1 B$, lanes 3 and 4). It is highly unlikely that this antibody also recognizes the $240 \mathrm{kDa}$ subunit of brain spectrin(240/235E), as our previous immunohistochemical analysis has demonstrated that this antibody primarily stains neuronal axons and does not stain dendrites, while brain $\operatorname{spectrin}(240 / 235 \mathrm{E})$ is located in neuronal dendrites and cell bodies (Riederer et al., 1986).

We have utilized the affinity purified antisera against mouse brain spectrin(240/235) and mouse rbc spectrin as specific probes for brain spectrin(240/235) and brain spectrin(240/235E), respectively, on immunoelectron microscopic analysis of mouse cerebellum.

\section{Immunoelectron microscopic localization of spectrin antigens}

Anti-mouse rbc spectrin

Examination of sagittal and coronal sections of the adult mouse cerebellum stained with anti-rbc spectrin (Figs. 2, 3), and conventionally prepared tissues (see Fig. 5), rcvealcd a spccific pattern of immunoreactivity. Brain spectrin(240/235E) was concentrated in the cytoplasm of neuronal cell bodies, dendrites, and postsynaptic areas. Immunoreactivity was particularly prominent subjacent to the plasma membrane, encompassing mitochondria, in association with microtubules, filaments, polyribosomes, and endoplasmic reticulum, and appearing as interconnecting cables within the cell. Axons, presynaptic areas, and nucleoplasm exhibited no reaction product. Glial cell bodies were stained, but glial processes were unreactive.

Detailed observation of the cerebellar cortex showed that the cell bodies of neurons were immunoreactive (Fig. 2, $A, C$ ). Within the cytoplasm, aggregates of stain were located subjacent to the plasma membrane, often extending considerable distance into the cytoplasm. In general, these peroxidase deposits measured between $200-650 \AA$ in diameter (Fig. $2 C$ ). Stain was distributed adjacent to mitochondria (Figs. $2, B, C ; 3 B$ ), fully encapsulating these organelles. Peroxidase was associated with structures resembling the endoplasmic reticulum (Fig. $2 C^{-}$), with the diameter of the stain deposits usually measuring 600-900 $\AA$; measurements of rough endoplasmic reticulum (including the endoplasmic cisterna and bordering ribosomes) in conventionally prepared specimens (Fig. $5 B$ ) was about $700 \AA$. Stain was often found in aggregates of varying size (500-1800 $\AA$ ) within the cytoplasm and resembled polyribosomal clusters (Fig. $5 B$ ) in conventional material (polyribosomes averaged $500-1300$ $\AA$ ). A stained meshwork associated with the cytoplasmic surface of the nucleus was observed (Fig. 2C). Quite prominent in the cytoplasm was the appearance of strandlike deposits with a diameter of 200-300 $\AA$ and lengths up to $2000 \AA$ that interconnected organelles, as well as organelles and the plasma membrane, within the cell body (Fig. 2C).

Stain extended into all dendritic processes and was found even in the smallest ramifications of these cell processes (Figs. $2 B ; 3$, $A-C$ ). As in the cell body, stain was localized subjacent to the plasma membrane, surrounded mitochondria, and strands of deposit interconnected organelles, as well as organelles and plasma membrane. Stain was often associated with long, straight elements; these deposits measured $250 \AA$ in diameter and appeared to correspond to microtubules (Figs. $2 B ; 3 A$ ), which in conventionally processed material (Fig. $5 A$ ) measured 210-250 $\AA$ in diameter. In the dendrites, peroxidase was also associated with filamentlike structures, $80-125 \AA$ in diameter (Fig. 2A), which were similar to neurofilaments (Fig. $5 C$ ). Small filaments, oriented perpendicular to microtubules (Fig. $2 A$ ), were also observed. These filaments were often noted to span 2-3 microtubules and measured up to $2000 \AA$ in total length. Peroxidase was also located in the synaptic spines of the dendrites (Fig. 3, $B, C$ and was especially associated with postsynaptic densities (Fig. 3C). Postsynaptic regions of dendrites, presumably the sites of axodendritic synapses, were also stained (Fig. $3 B$ ).

The cytoplasm of glial cells, but not nucleoplasm, was immunoreactive to anti-rbc spectrin (Fig. $3 D$ ). As in neurons, stain was found associated with the plasma membrane, around mitochondria, the nuclear envelope, and "strands" of deposit appeared to interconnect structural elements in the cell. Glial cell processes demonstrated no immunoreactivity (Figs. $2 B ; 3 D$ ). Occasionally, erythrocytes were encountered in blood vessels of the cerebellum. The rbcs were highly immunoreactive to antirbc spectrin IgG (Fig. 3E).

Control specimens stained with preimmune IgG or anti-rbc spectrin preabsorbed with rbc spectrin were not immunoreactive (Fig. 2D). Stain was sometimes found in glial cell coverings, and these deposits were randomly distributed.

Anti-mouse brain spectrin(240/235)

Examination of sagittal and coronal sections of the adult mouse cerebellum stained with anti-brain spectrin(240/235) (Fig. 4), along with conventionally prepared tissues (Fig. 5), revealed a specific pattern of immunoreactivity. Brain spectrin(240/235) was concentrated in axons and presynaptic elements of neurons, where it was associated with microtubules, synaptic vesicles, and mitochondria. Cell soma of neuronal cells exhibited a slight immunoreactivity, but dendrites, postsynaptic structurcs, nuclei, rbcs, and glia were unstained.

Detailed examination of the cerebellar cortex showed that axons were extremely immunoreactive (Fig. $4, A-E$ ). Stain was located subjacent to the axonal plasma membrane, encompassed the outer aspects of mitochondria, and formed interconnecting strands between organelles in the axon. In some cases, strands of deposit extended from the axolemma to organelles. Singular stain deposits of $200 \AA$ were often located in the axons and were believed to represent cross-sectional profiles of microtubules. Microtubules were seen to be intensely stained in longitudinal sections of axons (Fig. 4C). Myelinated (Fig. 4, $A-C$ ) and unmyelinated (Fig. $4, D, E$ ) axons were stained with anti-brain spectrin $(240 / 235)$. Immunoreactivity was noted in axonal elements contacting neuronal cell bodies and dendrites (Fig. $4, D$, $E$ ). Stain was quite prominently associated with synaptic vesicles in presynaptic areas (Fig $4 D$ ). Sometimes, a faint staining located subjacent to the neuronal cell body plasma membranes was recorded. Cell nuclei, dendrites, glial cell bodies and processes, endothelial cells, and erythrocytes showed no staining.

Control specimens stained with preimmune IgG or anti-brain spectrin IgG preabsorbed with brain spectrin were not immunoreactive (Fig. $4 F$ ). Some stain was located in glial cell coverings, and these deposits were randomly distributed.

\section{Discussion}

Despite our extensive knowledge about spectrin-related molecules in nonerythroid cells and tissues (for reviews, see Goodman and Zagon, 1984, 1986), few studies have approached the localization of spectrin-like proteins at the cellular level. Reports 

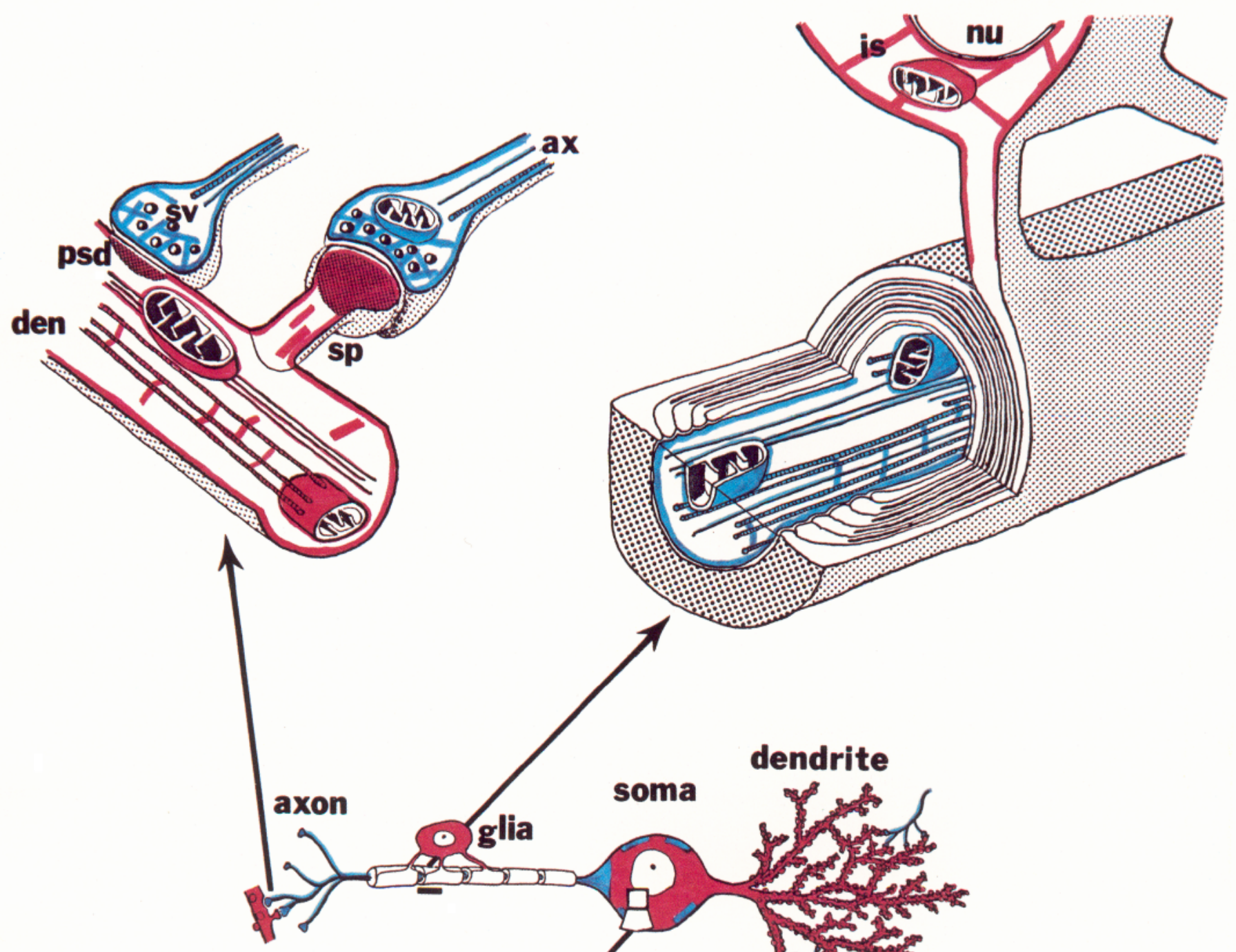

soma dendrite
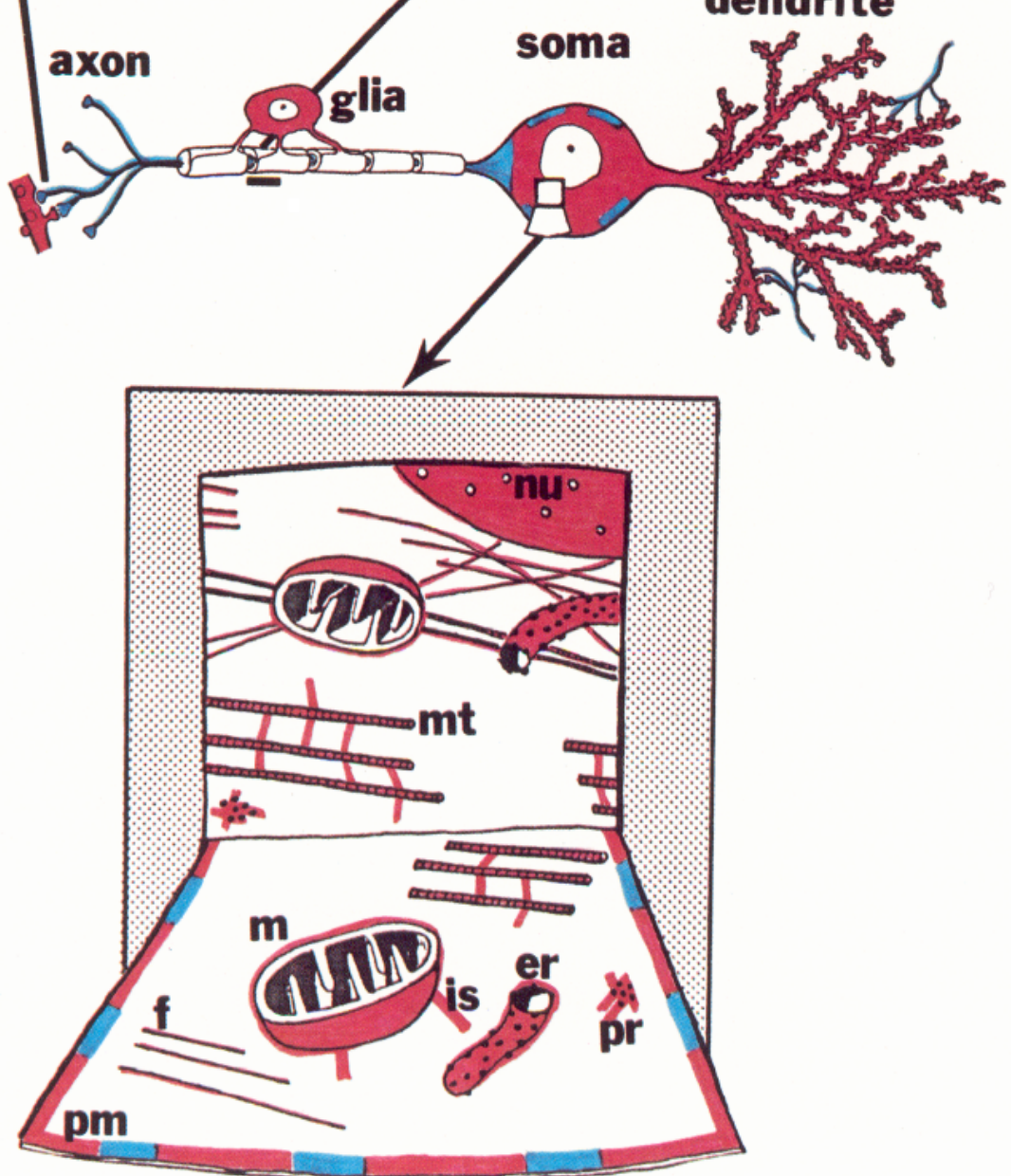
by Glenney et al. (1983) and Hirokawa et al. (1983) are the only investigations that have examined the distribution of spectrin at the ultrastructural level of resolution. Glenney et al. (1983) investigated the distribution of a spectrin-related molecule, TW$260 / 240$, in chicken intestinal brush border with ferritin-labeled antibodies. Electron-microscopic examination revealed molecules of TW-260/240 between the rootlets in the terminal web region and extending from the level of the apical plasma membrane to the base of the rootlets. Occasionally, ferritin was located on structures suggestive of fine filaments known to crosslink actin bundles. Utilizing quick-freeze, deep-etch preparations of mouse intestinal brush border, Hirokawa and colleagues (1983) reported that ferritin-conjugated antibodies to fodrin (brain spectrin) decorated thin (approximately $5 \mathrm{~nm}$ wide) fibrils, 100-200 nm long, that cross-linked bundles of actin filaments in the terminal web. Additionally, Hirokawa observed a few examples of similar antifodrin-reactive fibrils that linked actin bundles to the plasma membrane, coated and smooth vesicles, intermediate filaments, and the plasma membrane to vesicles. These results suggest that in situ, the antifodrin-reactive protein of brush border is a "fibrillar, multifunctional crosslinker." Thus, these studies reveal that spectrin not only bears an important relationship to the plasma membrane, but also has interactions with cytoplasmic elements.

The present study focuses on the localization of mammalian brain spectrin utilizing immunoelectron microscopic techniques. Riederer et al. (1986; also see Goodman and Zagon, 1986) have already demonstrated that there are at least 2 spectrin subtypes. Light-microscopic observations revealed that brain spectrin(240/235) is especially prominent in axons, whereas spectrin(240/235E) is present in neuronal cell bodies and dendrites, and in glial cells (also see Zagon et al., 1984). The present investigation confirms these earlier findings and provides the first detailed inspection of spectrin subtypes inside a single neuron or glial cell. Our results clearly show that the cellular location of spectrin molecules depends on the spectrin subtype explored. Thus, brain spectrin(240/235) is associated with the plasma membrane and cytoplasm of axons, while brain spectrin $(240 /$ $235 \mathrm{E}$ ) is associated with the plasma membrane and cytoplasm of neuronal soma and dendrites. Brain spectrin(240/235E) also is detected in association with the plasma membrane and cytoplasm of the glial cell body. We have observed that spectrin is attached to the cytoplasmic surface of mitochondria, endoplasmic reticulum, and the nuclear envelope. Quite importantly, our study demonstrates the presence of brain spectrin(240/235) in presynaptic terminals and brain spectrin $(240 / 235 \mathrm{E})$ in postsynaptic terminals. Our finding of brain spectrin(240/235E) in postsynaptic densities suggests that this is the subtype that was previously isolated from these structures by Carlin et al. (1983). Therefore, it appears that both the plasma membrane and the membranes of organelles contain a spectrin meshwork in neurons and glia. By analogy to the erythrocyte (see Goodman and Zagon, 1984), brain spectrin(240/235E) on membranes of cell bodies and dendrites may play a role in stabilizing these membranes, supporting the shape of soma and dendrite, regulating lateral mobility of molecules through the membrane, and controlling phospholipid asymmetry. Brain spectrin(240/235), which is associated with the plasma membrane of axons and presynaptic terminals, as well as the cytoplasmic surface of mitochondria and synaptic vesicles, may also have the same function(s) in axons and synapses that brain spectrin(240/235E) has in cell bodies and dendrites. Additionally, brain spectrin(240/235) may be important in axonal transport of organelles (e.g., mitochondria) and vesicles (e.g., synaptic vesicles), as well as in synaptic transmission. It is interesting to note that the initial studies on axonal transport of fodrin demonstrated 2 classes of movement. One class of fodrin migrated slowly down the axon along with other cytoskeletal elements. A second class of fodrin moved down the axon at a rate of $\sim 40 \mathrm{~mm} / \mathrm{d}$, which represented the speed at which mitochondria traveled down the axon (Lorenz and Willard, 1978). It also may be relevant that brain spectrin has recently been demonstrated to hind synapsin I (Baines and Bennett, 1985; Goodman and Zagon, 1986; Krebs et al., 1986) at its terminal ends (Goodman and Zagon, 1986; Krebs et al., 1986). Therefore, the association of spectrin with synaptic vesicles visualized in this study is likely through synapsin I. This interaction may be essential for either the translocation of synaptic vesicles towards the presynaptic membrane or the prefusion events at the membrane surface (Goodman and Zagon, 1986; Krebs et al., 1986).

Both spectrin subtypes were extensively associated with microtubules. Moreover, at least one type of spectrin, i.e., brain spectrin(240/235E), appears to crosslink microtubules. This association with microtubules may be important in microtubulemembrane interactions, strengthening of the microtubule matrix, and perhaps in axonal transport and translocation of synaptic vesicles. The extensive spectrin-microtubule interaction, as well as the suggestive spectrin-neurofilament interaction, recorded in our electron micrographs is consistent with the recent reports of the coisolation of fodrin (brain spectrin) with microtubules isolated under stabilizing conditions (Fach et al., 1985) and the coprecipitation of MAP1, MAP2, actin, and neurofilaments with fodrin antibody in rat cerebral cortex preparations (Siman and Lynch, 1985). In the present study, both spectrin subtypes were associatcd with filaments of a smaller diametcr than microtubules; however, it was difficult to distinguish peroxidase-stained neurofilaments from microfilaments. Double-label, immunoelectron microscopic studies such as those using varied size colloidal gold will be required to make that distinction. In addition, immunogold technology will eliminate the possibility of translocation of the reaction product from the site of antibody binding, a potential problem with the immunoperoxidase method. An intriguing development of our study is the finding of brain spectrin in numerous strands that connect organelles to the plasma membrane and organelles to each other in neuronal and glial cells. We do not as yet know the identity of these spectrin-containing strands, but they may play a role in the placement and, perhaps, movement of organelles within the cytoplasmic matrix.

In Figure 6 we summarize our knowledge of brain spec$\operatorname{trin}(240 / 235)$ and brain spectrin(240/235E) within neural cells. The extensive association of brain spectrin subtypes with cytoplasmic organelles and cytoskeletal structures demonstrates that the functions of these subtypes will be far more numerous and complex than the function of rbc spectrin, which laminates the cytoplasmic surface of the erythrocyte plasma membrane.

\section{References}

Baines, A., and V. Bennett (1985) Synapsin I is a spectrin binding protein immunologically related to erythrocyte protein 4.1 . Nature 312: 410-413.

Carlin, R. K., D. C. Bartelt, and P. Siekevitz (1983) Identification of

Figure 6. Schematic representation of the localization of spectrin subtypes in the mammalian nervous system. Spectrin subtypes are color-coded with red indicating the distribution of brain spectrin $(240 / 235 \mathrm{E})$ and blue denoting brain spectrin $(240 / 235)$. Abbreviations: $a x=$ axon; den $=$ dendrite; $e r=$ endoplasmic reticulum; $f=$ filaments; $i s=$ interconnecting strands; $n u=$ nucleus; $m=$ mitochondria; $m t=$ microtubules; $p m=$ plasma membrane; $p r=$ polyribosomes; $p s d=$ postsynaptic density; $s p=$ dendritic spine. 
fodrin as a major calmodulin-binding protein in postsynaptic density preparations. J. Cell Biol. 96: 443-448.

Cheney, R., N. Hirokawa, J. Levine, and M. Willard (1983) Intracellular movement of fodrin. Cell Motility 3: 649-655.

Davis, J. Q., and V. Bennett (1984) Brain ankyrin: A membraneassociated protein with binding sites for spectrin, tubulin, and the cytoplasmic domain of the erythrocyte anion channel. J. Biol. Chem. 259: 13550-13559.

Fach, B. L., S. F. Graham, and R. A. B. Keates (1985) Association of fodrin with brain microtubules. Can. J. Biochem. Cell Biol. 63: 372381.

Glenney, J. R., Jr., and P. Glenney (1983) Spectrin, fodrin, and TW260/ 240: A family of related proteins lining the plasma membrane. Cell Motility 3: 671-682.

Glenney, J. R., Jr., P. Glenney, and K. Weber (1982) F-actin-binding and cross-linking properties of porcine brain fodrin, a spectrin-related molecule. J. Biol. Chem. 257: 9781-9787.

Glenney, J. R., Jr., P. Glenney, and K. Weber (1983) The spectrinrelated molecule, TW-260/240, cross-links the actin bundles of the microvillus rootlets in the brush borders of intestinal epithelial cells. J. Cell Biol. 96: 1491-1496.

Goodman, S. R., and S. C. Weidner (1980) Binding of spectrin tetramers to human erythrocyte membranes. J. Biol. Chem. 255: 80828086.

Goodman, S. R., and I. S. Zagon (1984) Brain spectrin: A review. Brain Res. Bull. 13: 813-832.

Goodman, S. R., and I. S. Zagon (1986) The neural cell spectrin skeleton: A review. Am. J. Physiol. 250: C347-C360.

Goodman, S. R., I. S. Zagon, and R. R. Kulikowski (1981) Identification of a spectrin-like protein in nonerythroid cells. Proc. Natl. Acad. Sci. USA 78: 7570-7574.

Goodman, S. R., S. A. Weidner, E. Eyster, and J. J. Kesselring (1982) Binding of spectrin hereditary spherocyte membranes. J. Mol. Cell. Cardiol. 14: 91-97.

Goodman, S. R., I. S. Zagon, C. F. Whitfeld, L. A. Casoria, S. B. Shohet,
S. E. Bernstein, P. J. McLaughlin, and T. L. Laskiewicz (1983) A spectrin-like protein from mouse brain membranes: Phosphorylation of the 235,000-dalton subunit. Am. J. Physiol. 247: C61-C73.

Hirokawa, N., R. E. Chency, and M. Willard (1983) Location of a protein of the fodrin-spectrin-TW260/240 family in the mouse intestinal brush border. Cell 32: 953-965.

Krebs, K. E., R. K. Sihag, R. Higbee, I. S. Zagon, and S. R. Goodman (1985) Synapsin I, a species of brain protein 4.1, binds to the ends of brain spectrin tetramer. J. Cell Biol. 101: 287a.

Laemmli, U. K. (1970) Cleavage of structural proteins during the assembly of the head of bacteriophage $T_{4}$. Nature 227: 680-685.

Lazarides, E., and W. J. Nelson (1983) Erythrocyte and brain forms of spectrin in cerebellum: Distinct membrane-cytoskeletal domains in neurons. Science 222: 931-933.

Levine, J., and M. Willard (1981) Fodrin: Axonally transported polypeptides associated with the internal periphery of many cells. J. Cell Biol. 90: 631-643.

Lorenz, T., and M. Willard (1978) Subcellular fractionation of intraaxonally transported polypeptides in the rabbit visual system. Proc. Natl. Acad. Sci. USA 75: 505-509.

Riederer, B. M., I. S. Zagon, and S. R. Goodman (1986) Brain spectrin(240/235) and brain spectrin(240/235E): Two distinct spectrin subtypes with different locations within mammalian neural cells. J. Cell Biol. 102: 2088-2097.

Siman, R., and G. Lynch (1985) Fodrin: Skeletal protein cross-linker in rat brain subcellular fractions. Soc. Neurosci. Abstr. Vol. 775.

Towbin, H., T. Staehelin, and J. Gordon (1979) Electrophoretic transfer of proteins from polyacrylamide gels to nitrocellulose sheets: Procedure and some applications. Proc. Natl. Acad. Sci. USA 76: 4350 4354.

Zagon, I. S., and P. J. McLaughlin (1981) Naloxone prolongs the survival time of mice treated with neuroblastoma. Life Sci. 28: 10951102.

Zagon, I. S., P. J. McLaughlin, and S. R. Goodman (1984) Localization of spectrin in mammalian brain. J. Neurosci. 4: 3089-3100. 